
EESTI NSV TEADUSTE AKADEEMIA TOIMETISED. 32. KOIDE
KEEMIA. 1983, NR. 1

ИЗВЕСТИЯ АКАДЕМИИ НАУК ЭСТОНСКОЙ ССР. ТОМ 32 Химия. 1983, № 1

удК 66.023.2

\author{
Г. РАЯЛО, Т. ПЕТРОВСКАЯ, Т. ВОЛЕНС, А. ФЕТИСОВ
}

\title{
СТРУКТУРА ПОТОКОВ В ГИДРОХЛОРАТОРЕ ТИПА НАСАДОЧНОЙ КОЛОННЫ
}

G. RAJALO, T. PETROVSKAJA, T. VOLENS, A. FETISSOV. VOOLUSTE STRUKTUUR TÄIDISKOLONNI TUUPI HODROKLORAATOREIS

G. RAJALO, T. PETROVSKAYA, T. VOLENS, A. FETISSOV. FLOW STRUCTURE IN THE PACKED COLUMN HYDROCHLORATOR

(Представил И. Клесмент)

Гидрохлорирование жидких легкокипящих алкадиенов - изопрена, пиперилена и диметилбутадиена - газообразным хлористым водородом проводится в реакторе (гидрохлораторе) типа насадочной колонны, где сверху вниз стекает жидкость, содержащая исходный алкадиен и продукты реакции, а снизу вверх с медленной скоростью поднимается газовая фаза - хлористый водород с парами жидких компонентов. В колонне происходит многокомпонентный разнонаправленный межфазный массообмен (абсорбция, 'испарение, конденсация), сопровождаемый медленной химической реакцией в жидкой фазе. Опираясь на результаты экспериментальных исследований, мы справедливо можем выразить структуру потоков в жидкой фазе моделью идеального вытеснения с застойными зонами ['], по которой материальный баланс любого $i$-го компонента жидкой фазы в объеме насадки высотой $\delta l$ выражается следующими уравнениями.

Для проточной зоны:

$\alpha H \frac{\pi d_{\kappa}^{2}}{4} \frac{\delta C_{i}}{\delta t}-Q_{ж} \frac{\delta C_{i}}{\delta l} \pm \alpha H \frac{\pi d_{\mathrm{\kappa}}^{2}}{4} r_{i}+N_{i}+\alpha \beta H \frac{\pi d_{\mathrm{\kappa}}^{2}}{4}\left(C_{i}-C_{i 3}\right)=0$.

Для застойной зоны:

$(\alpha-1) H \frac{\pi d_{\mathrm{k}}^{2}}{4} \frac{\delta C_{i 3}}{\delta t} \pm(\alpha-1) H \frac{\pi d_{\mathrm{K}}^{2}}{4} r_{i 3}-\alpha \beta H \frac{\pi d_{\mathrm{k}}^{2}}{4}\left(C_{i}-C_{i 3}\right)=0$.

В этих уравнениях $Q_{\text {ж }}$ - объемная скорость жидкой фазы; $C_{i}$ и $C_{i 3}$ - концентрации $i$-го компонента соответственно в проточной и застойной зонах; $t$ - время; $d_{\mathrm{k}}$ - диаметр колонны; $H$ - удерживающая способность насадки; $\alpha-$ доля объема проточных зон; $\beta-$ коэффициент конвективного обмена между проточной и застойной зонами, представляющий собой объемный поток вещества, отнесенный к единице объема проточной зоны; $r_{i}$ и $r_{i 3}-$ скорость химической реакции по $i$-му компоненту соответственно в проточной и застойной зонах (с положительным 
знаком для компонентов, расходуемых в ходе реакции); $N_{i}-$ скорость межфазной массопередачи $i$-го компонента в направлении от жидкости к газу, отнесенная к единице высоты колонны. Для компонента, не участвующего ни в химической реакции, ни в межфазной массопередаче, например для инертного трассера, члены $r_{i}, r_{i 3}$ и $N_{i}$ равняются нулю, и вышеприведенные уравнения заметно упрощаются.

Содержащиеся в уравнениях (1), (2) три неизвестных параметра $H, \alpha$ и $\beta$ зависят от гидродинамических условий проведения процесса. Они определяются на основе опытов с импульсным вводом инертного трассера в поток жидкости, входящий в аппарат, и регистрацией соответствующей концентрационной кривой ( $C$-кривой) в выходящем потоке. В [ $\left.{ }^{2}\right]$ приведены результаты экспериментальных исследований, проведенных в лабораторной стеклянной колонне диаметром 25 мм и высотой насадки 1,0 м. В качестве насадки служили стеклянные кольца Рашига размером $4,5 \times 4,5 \times 0,7$ м. В качестве трассера использовали краситель. В результате исследований была найдена зависимость.

$$
H=3,08(\mathrm{Fr} / \mathrm{Re})^{1 / 3}+0,0262,
$$

где $\mathrm{Re}=u_{0} l_{0} / \mu$ - критерий Рейнольдса; Fr $=u_{0}^{2} / g l_{0}$ - критерий Фруда. В этих критериях $u_{0}$ - линейная скорость жидкой фазы, отнесенная к общему поперечному сечению колонны; $l_{0}$ - номинальный размер насадки; @ - плотность; $\mu$ - динамический коэффициент вязкости; $g$ ускорение свободного падения.

Основываясь на вышеуказанных экспериментах мы в данной работе сделали дополнительные обобщения для определения параметров $\alpha$ и $\beta$. В первую очередь остановимся на интерпретации зависимости (3). Путем теоретического анализа можно доказать, что в случае гидрохлорирования, где течение жидкости определяется в основном силами тяжести и внутреннего трения, первый член уравнения (3) выражает динамическую $\left(H_{д}\right)$, а второй - статическую $\left(H_{\text {ст }}\right)$ составляющие удерживающей способности насадки. Доля объема проточных зон соответствует отношению

$$
\alpha=H_{д} / H=1-H_{\mathrm{c \tau}} / H .
$$

Коэффициент конвективного обмена между проточной и застойной зонами можно определить из уравнения

$$
\beta=\frac{2(1-\alpha)^{2} u_{\mathrm{mp}}}{\sigma^{2} L},
$$

где $u_{\text {пр }}=4 Q_{ж} / \alpha H \pi d_{\text {к }}^{2}$ - линейная скорость течения жидкости в проточной зоне; $L$ - общая высота слоя насадки. Дисперсия $\sigma^{2}$ определяется как второй центральный момент распределения времени пребывания частиц в безразмерных единицах. На основе экспериментальных данных, полученных на лабораторной установке, нами найдено нижеследующее критериальное уравнение для расчета коэффициента конвективного межзонового массообмена:

$$
S=\frac{\beta L}{u_{\text {пр }}}=0,11 \mathrm{Ga}^{0,22},
$$

где критерий Галилея $\mathrm{Ga}=l_{0}^{3} \mathrm{Q}^{2} g / \mu^{2}$. Невысокий коэффициент корреляции этого уравнения $(R=0,65)$ характерен для гидродинамических зависимостей, получаемых на основе моментов выше первого порядка.

Далее мы провели опыты в полупромышленном гидрохлораторе диаметром 200 мм и с высотой насадки 3,3 м. В качестве насадки служили 
кольца Рашига из пропитанного графита $($ АТМ) размером $16 \times 16 \times 4$ мм. Во избежание нежелательных, но характерных для полупромышленных установок конечных эффектов мы в этих опытах применяли в качестве трассера-индикатора радиоактивный изотоп бром-82 в ортонитробензоле. При выборе этого трассера учитывались ядерно-физические характеристики изотопа и физико-химические свойства соединения, в т. ч. хорошая растворимость в исследуемой жидкой фазе. Измерение относительной плотности $\gamma$-квантов, излучаемых трассером, осуществляли радиометром MBP-5, детекторы которого располагались у входа и выхода жидкой фазы и с равномерными интервалами по длине насадки. Опыты были проведены при разных рабочих режимах гидрохлорирования изопрена.

В результате статистического анализа полученных $C$-кривых выяснилось, что если принять во внимание чистое время пребывания частиц жидкости в насадке (по показаниям детекторов, расположенных на обоих концах насадки), то получится зависимость удерживающей способности насадки от гидродинамических условий течения жидкости, которая практически полностью совпадает с уравнением (3). При этом следует отметить, что в случае применения красителя в качестве трассера получают повышенное значение удерживающей способности за счет задержки жидкости в нижней части колонны $\left[{ }^{2}\right]$. Что касается коэффициента межзонового конвективного массообмена, то его значение в случае применения полупромышленной установки и используемой в ней графитовой насадки примерно на $60 \%$ ниже значения, полученного по уравнению (6).

Далее мы изучили структуру потоков в газовой фазе. Для этого проводили опыты в полупромышленном гидрохлораторе, работающем в режиме гидрохлорирования изопрена. В качестве газового трассера служил радиоактивный криптон-85, который вводили импульсно в поток газообразного хлористого водорода в нижней части колонны. Относительную плотность $\gamma$-квантов в разных точках на оси колонны измеряли по описанной выше методике. По полученным $C$-кривым определяли среднее время пребывания газовых частиц и дисперсию времени пребывания на разной высоте насадки. Найденные нами значения дисперсии безразмерного времени пребывания частиц газа в насадке лежат в пределах $\sigma^{2}=0,06-0,09$. Этому соответствуют значения критерия Пекле $\mathrm{Pe}=$ $=u_{0} l_{0} / D=22-33$, что допускает возможность применения модели идеального вытеснения для описания структуры потоков в газовой фазе при незначительных допущениях.

\section{ЛИТЕ РА Т У Р А}

1. Hoogendoorn, C. J., Lips, J. Axial mixing of liquid in gas-liquid flow through packed beds. - Can. J. Chem. Eng., 1965, 43, N 6, 125-151.

2. Воленс T., Петровская T., Раяло Г. Продольное перемешивание и задержка жидкости в насадочной колонне при малой скорости газового потока. - Изв. АН ЭССР. Хим., Геол., 1976, 25, № 2, 132-135.

Ннститут химии

Академии наук Эстонской ССР
Поступила в редакцию 12/VII 1982 